\title{
Analysis of electromagnetic pollution by means of geographic information system
}

\author{
Vladimir Henao-Cespedes, Yeison Alberto Garcés-Gómez \\ Universidad Católica de Manizales, Unidad Académica de Formación en Ciencias Naturales y Matemáticas, Colombia
}

\begin{tabular}{l}
\hline \hline Article Info \\
\hline Article history: \\
Received Sep 28, 2020 \\
Revised May 24, 2021 \\
Accepted Jun 12, 2021 \\
\hline
\end{tabular}

\section{Keywords:}

Base telecommunication station Electromagnetic pollution

GIS

Mobile phone

Non-ionizing radiation

\begin{abstract}
Currently, telecommunications systems have become more widespread and there is still a discrepancy between whether or not non-ionizing radiation produces health problems in living beings at cellular level. From an experimental point of view, it is interesting to raise the correlation of high levels of electromagnetic pollution with health problems in urban populations which would make it possible to clearly determine the effects of this type of radiation on human health and the environment. By means of remote sensing, a geographic information system (GIS) has been developed for the analysis of electromagnetic pollution levels generated by emissions from non-ionizing radiation (NIR) sources in a city. A method for measuring electromagnetic pollution was applied, which allows the generation of a table of attributes of the GIS that is the input to generate by inverse distance weighting (IDW), the layer of electromagnetic pollution. The method, as a case study, was applied in the city of Manizales, located in Colombia, obtaining as a result a layer that allows evidence that the highest levels of electromagnetic pollution are concentrated in the most central area of the city. In this way, the effects of NIR on public health can be analyzed by means of correlations.
\end{abstract}

This is an open access article under the CC BY-SA license.

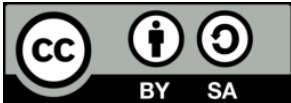

\section{Corresponding Author:}

Vladimir Henao-Cespedes

Unidad Académica de Formación en Ciencias Naturales y Matemáticas

Universidad Católica de Manizales

Cra 23 No 60 - 63, Manizales, Caldas, Colombia

Email: vhenao@ucm.edu.co

\section{INTRODUCTION}

Telecommunication systems, as we know them today, work by using electromagnetic radiation for their operation. Electromagnetic radiation is categorized into ionizing radiation (IR) and non-ionizing radiation (NIR), the latter being associated with telecommunication systems. Despite its emergence in commercial form in the mid-1980s, and its popularization at a global level around the year 2000, today, almost 40 years later, both the general public and the scientific community continue to question whether NIR emissions from mobile phone base stations (BTSs) are harmful to health. This questioning has continued to gain momentum, especially now that $5 \mathrm{G}$ technology is being deployed worldwide, which, as indicated by [1] will be a disruptive change from $4 \mathrm{G}$ to $5 \mathrm{G}$, leading to an increase in data speed and a decrease in latency. While this deployment of $5 \mathrm{G}$ technology is important for technological advancement, it presupposes by some sectors of society an increased risk to public health. These emissions are generated by artificial systems that have become a source of electromagnetic pollution, which in many cases is much stronger than any natural source of electromagnetic fields or radiation [2], [3].

Electromagnetic pollution levels may be increasing due to the rise of mobile devices in recent years [4], which are sources of non-ionizing radiation (NIR). By 2020, the number of mobile devices may have 
already exceeded 5 billion, and it is estimated that this number will reach 50 billion in the next decade, considering the proliferation of the internet of things (IoT) sensors [5]-[8]. On the other hand, non-ionizing radiation is being emitted by other telecommunication systems with technologies other than $2 \mathrm{G}, 3 \mathrm{G}, 4 \mathrm{G}$ and $5 \mathrm{G}$, which although, as [9] says, are fantastic for IoT solutions, they present a disadvantage in terms of cost, and therefore lower cost systems are required for which new companies can emerge with this type of technology. Therefore, the world of IoT is making inroads into networks such as LoRaWAN which makes use of LoRa technology. Given the increase in devices and the incursion of new communication technologies, and seeking to answer the question that has been raised in recent years, there are several authors who have tried to address their response with different types of studies, these authors have observed two trends with respect to the results, one trend indicates that the studies do not have the robustness from their experimental design to relate exposure to sources of NIR with biological effects [10], [11]. Another trend indicates that if it is possible to relate NIR sources to biological effects [12]-[18] In this stream can be framed what is proposed by [19], by indicating that the mechanism through which NIR causes effects is oxidative stress, for which NIR must not have sufficient energy to generate modifications at the molecular level.

A review of the literature on the possible health effects caused by NIR allows us to obtain a graphical network of co-occurrences, which can be seen in Figure 1, in which we can see the main key words used in studies that seek to respond to the effects that NIR can cause on health. In Figure 1, it is evident that one of the nodes with an important weight is oxidative stress, which could indicate that the scientific community is addressing the possibility that effects are generated not only by the intensity of NIR, but that these can be generated by other mechanisms.

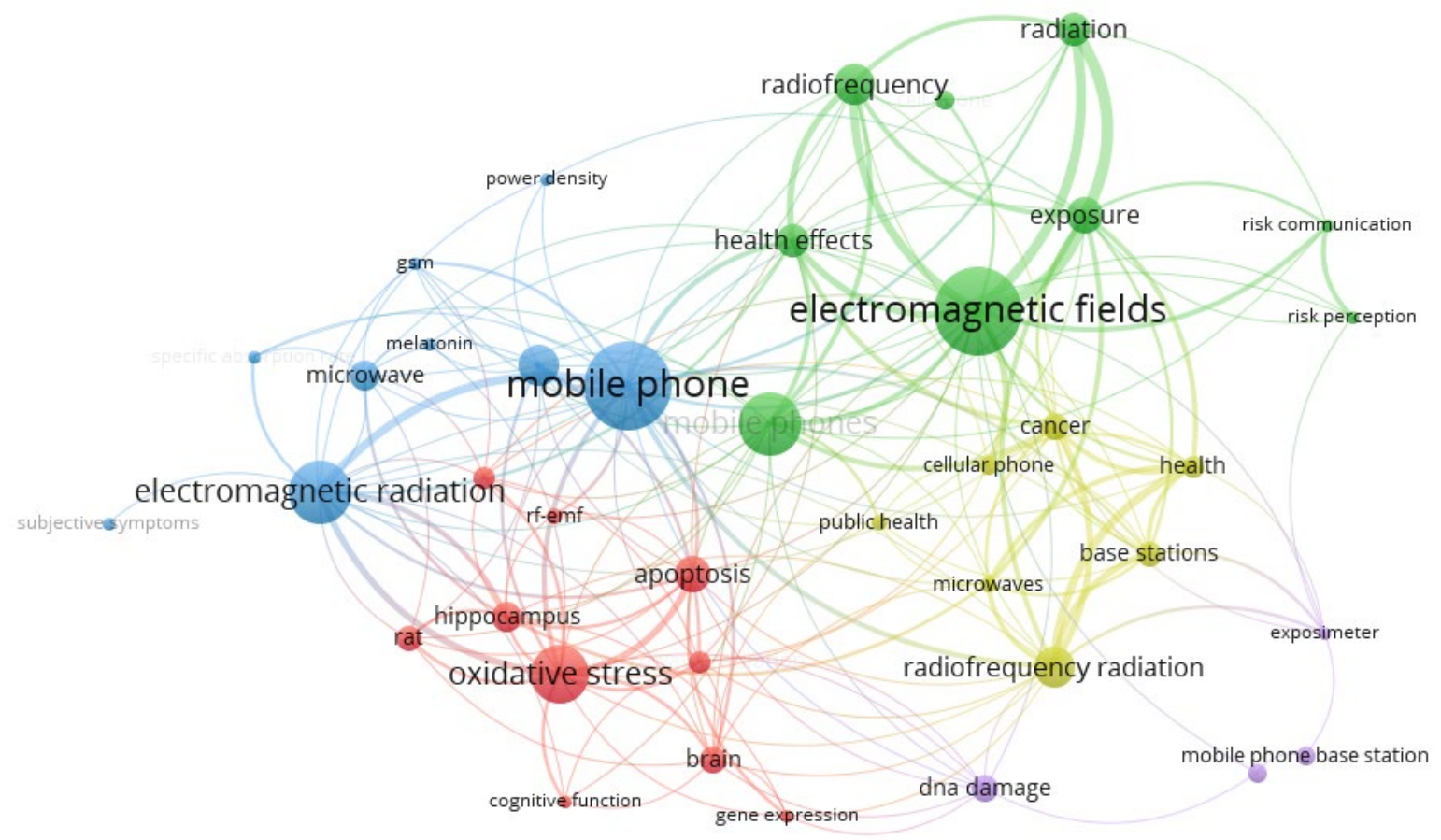

Figure 1. Concurrency network for the search equation ("health *" AND ("* radiation") AND "electromagnetic" AND ("mobile phone\$" OR "base station\$") AND "exposure"), generated with VOSviewer [20]

Some studies have looked for the relationship that may exist between emissions from NIR sources with health effects, by correlating the locations of NIR emission devices, more specifically telecommunication base stations (BTS), with cases of deaths from some diseases [13], with psychological and psychobiological reactions [17], and with anxiety and depression [12]. In that sense, to have a geographic information system (GIS) that allows to store, to visualize and to analyze the levels of contamination EM emitted by the sources of NIR and the parameters of health that are wanted to consider, that is to say, a system of geographic information for analysis of contamination EM, can be an important 
instrument to continue deepening in the studies of spatial and temporal correlation between the emissions of NIR and affectations of the health.

This study was conducted in Manizales, a municipality in Colombia located in the department of Caldas. Manizales has a rugged topography, so it must have a significant number of telecommunications base stations, to cover the areas of darkness that can be generated due to the topography, thus meeting the requirements of the population in the urban area, in terms of communications. This situation, according to the authors consulted, could generate public health problems due to the proximity of highly populated communities to radiation sources, and taking into account that NIR has been classified by the WHO as a possible carcinogen [21], it is important to develop tools that allow the study of prolonged exposure to high levels of radiation. This article presents the development of the electromagnetic pollution layer for a GIS that allows the generation of a dynamic map of exposure to such pollution.

\section{MATERIALS AND METHODS}

\subsection{Proposed electromagnetic pollution geographic information systems}

A geographic information system allows the consolidation of information in a georeferenced manner [22], so that it can be represented graphically, and thus support decision making in an effective manner. In that sense, for a GIS that is focused on the electromagnetic pollution, the information that must be counted on is the levels of this pollution, the sensitive sites (schools, hospitals, among others), the affectations of health under study. Regarding GIS and their relationship with NIR, there are studies such as the one developed by [23], in which they carry out measurements of electromagnetic radiation and store the results in a geographic information system for the purpose of carrying out statistical studies on the spatial distribution of field levels in the areas of study. Another similar study is carried out by [24], but this time for broadcasts in the AM band.

On the other hand, authors such as [25], [26] have implemented GIS to perform both spatial and temporal analyses of exposure to electromagnetic fields. Attempting to implement a non-GIS system to perform this type of analysis can be complex due to the volume of data that would be required to map an entire city, but the use of GIS-associated techniques can solve this problem, as proposed by Briggs [27] who managed to implement a GIS-based exposure model, thanks to the facilities offered by GIS techniques to perform the complex calculations that are required to generate a radio-frequency power density model around mobile phone stations. In the sense of correlating effects with health [28] present a GIS that allows georeferencing patients and correlating their locations with environmental pollution, especially electromagnetic pollution and cases of childhood leukemia. Thus, achieving the development of a GIS that includes information on electromagnetic pollution is an interesting contribution to studies that seek to clarify the possible risks generated by mobile phone stations (BTS) in cities.

\subsection{Development of the geographic information system GIS for electromagnetic pollution generated by BTS}

The GIS developed in this article has 4 modules, one of which requires as input to generate the layer of electromagnetic pollution, the values of this, for this is done using a methodology previously raised and validated in [29]. Figure 2 shows a simplified model of the data generated for the GIS developed:

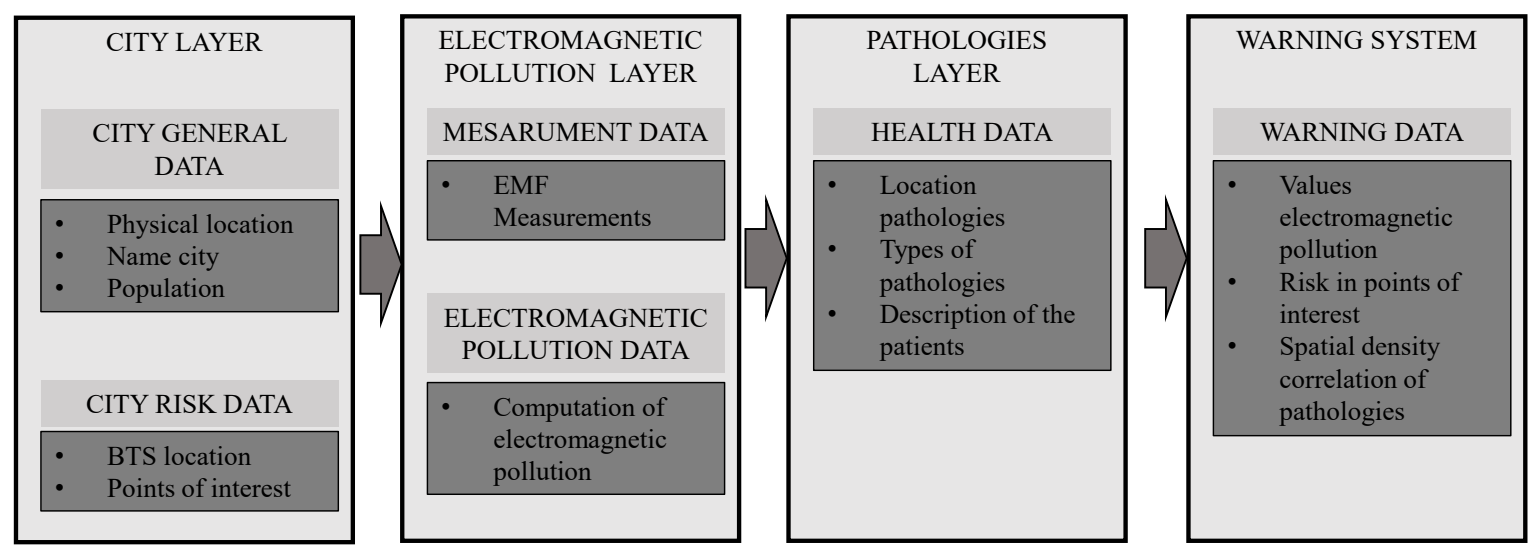

Figure 2. Simplified model of the GIS information layers 
The simplified model shown in Figure 2 has three modules. The first module allows the generation of the city layer, where it is possible to identify the locations of the BTS and some points of interest for future studies, such as: Hospitals, clusters of some specific diseases, schools, among others. The second module is related to the layer of electromagnetic pollution, there is included the process of EMF measurement and based on these calculate the value of pollution in the measurement sites. The third module concentrates the information related to the pathologies, such as the type, location and general description of the patients (age, sex, among others). Finally, the fourth module is a warning system that allows, based on previously generated data, to carry out studies on correlations between contamination values and spatial density of pathologies.

The methodology to obtain the contamination values [29], establishes that assuming that the environment behaves as a linear system (i.e. multiple frequencies enter the environment and the environment does not modify them), and that different sources of NIR can co-exist at a measurement site, it will then be possible to apply the principle of source overlapping, and to make measurements of the EMF emitted by these and thus use the (1), which allows the value of EM pollution at a point of interest to be obtained, considering all possible sources of NIR:

$$
\operatorname{OCOEM}(t)=\sum_{i=0}^{k} a_{k} e^{j i \omega_{i} t}
$$

where:

$a_{k}$ could well be, the power density denoted by $S$, the magnetic field strength $H$, the electric field strength $E$. $K$ is the k-source of incident and evaluated NIR at the measurement site. $\omega_{i}$ is the operating frequency of the i-th NIR source.

To obtain the data that are associated to the EM pollution layer, a measurement campaign was carried out in the city of Manizales, which allowed calculating georeferenced EM pollution values. These data allowed the generation of a table of attributes as shown in Figure 3 of the GIS.

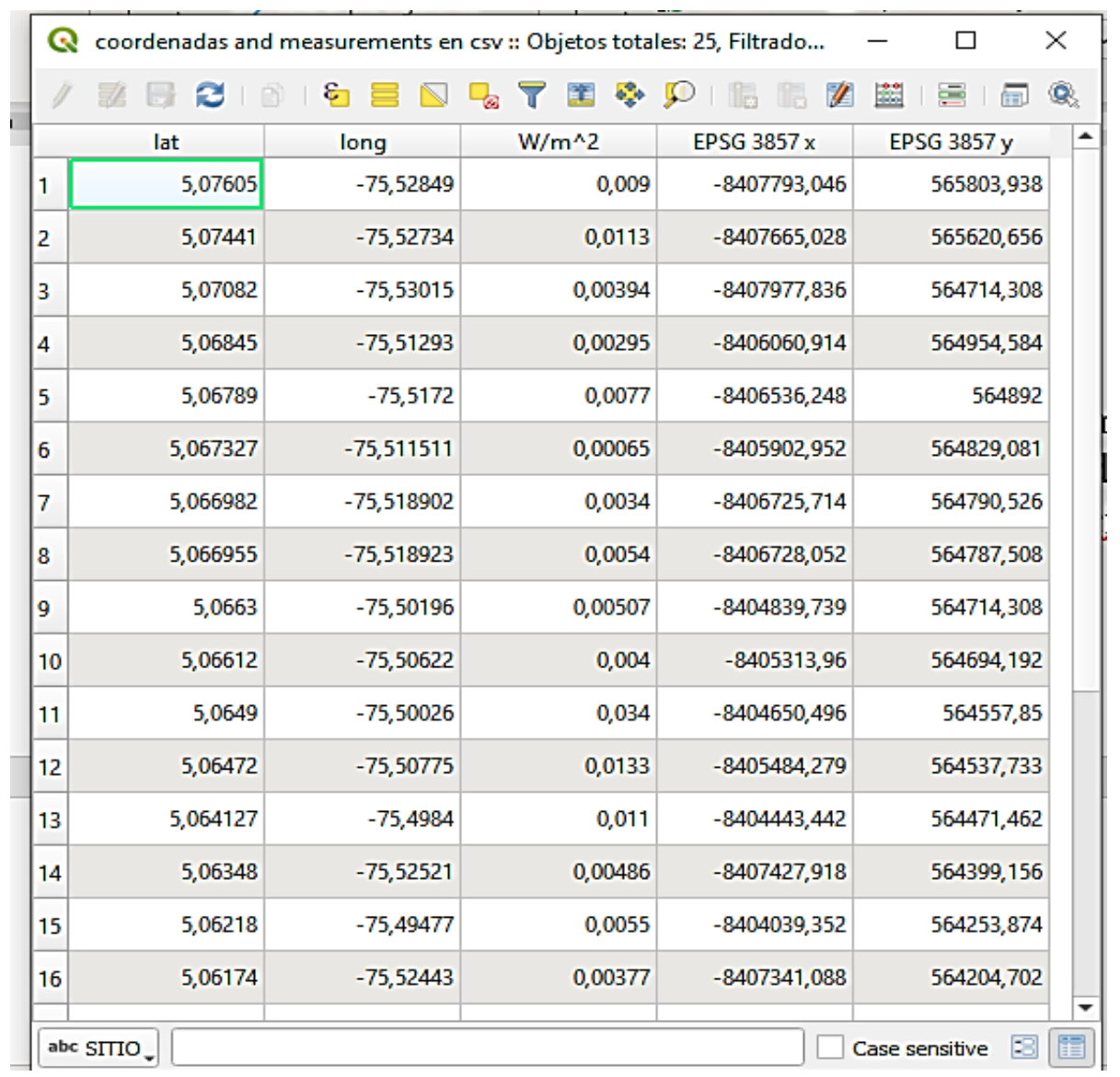

Figure 3. Table of attributes of sites of interest, values of $\operatorname{OCOEM}\left(\mathrm{W} / \mathrm{m}^{2}\right)$ in the third column, first and second column site coordinates 
Once the attribute table was generated, the IDW interpolation, inverse distance weighting, was applied to the measurement data obtained, according to [30] the sample points are weighted during interpolation, so that the influence of one point in relation to another decreases with the distance from the unknown point you want to create. IDW is a technique that uses weighting logic to create surface data and weight with a distance, which means that the further the distance, the lower the weight value [31]. Finally, it was possible to generate the electromagnetic pollution layer of the GIS, which can be seen in Figure 4. In relation to the frequencies selected to carry out the measurement campaign, the maximum permissible exposure limits, $E$ and $S$, in the general public zone, according to the laws of the Republic of Colombia [32], which is based on the ICNIRP regulations [33], are shown in Table 1.

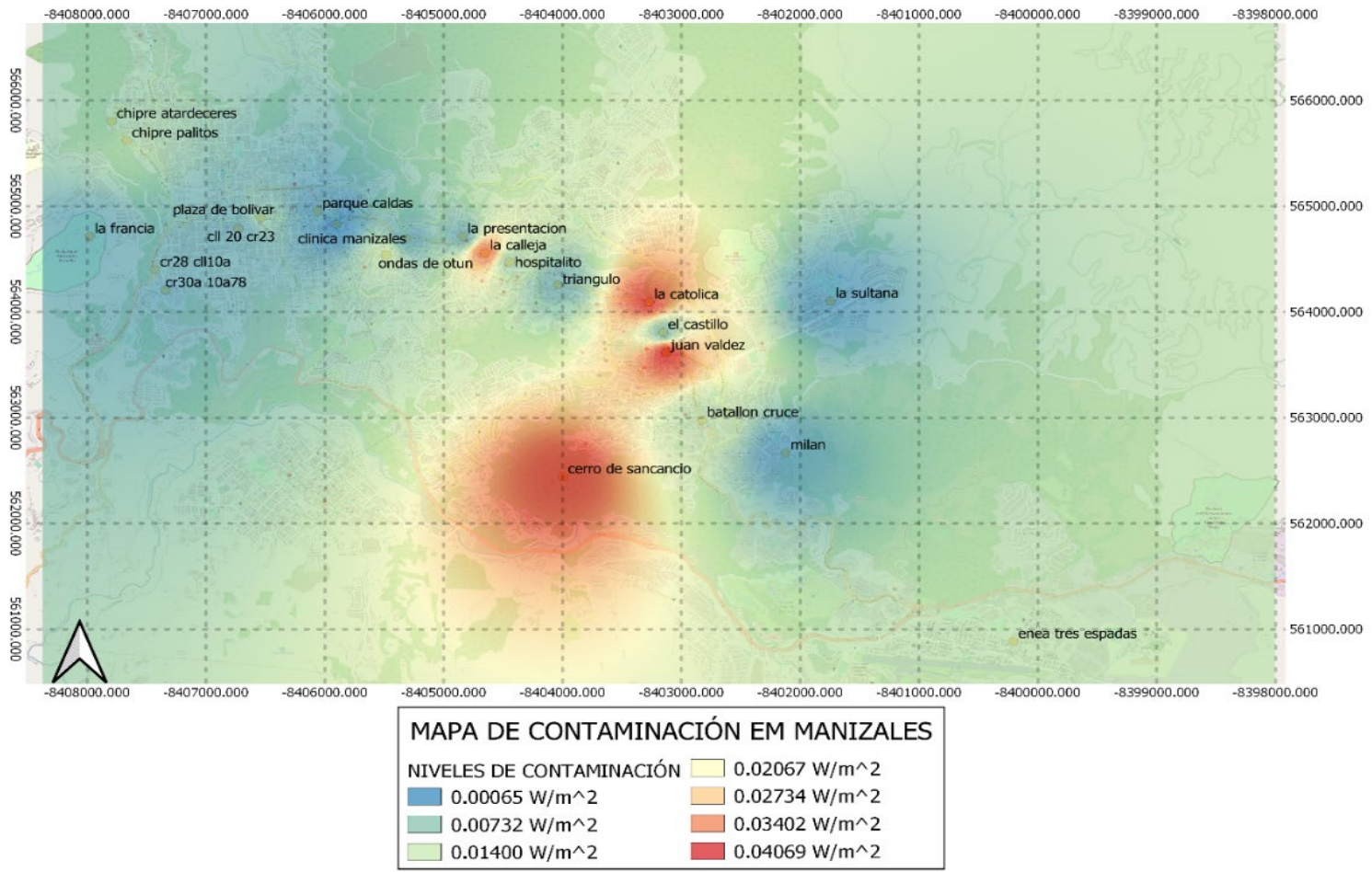

Figure 4. Layer of EM pollution levels in the city of manizales

Table 1. Maximum exposure limits

\begin{tabular}{cccc}
\hline Frequency $(\mathrm{MHz})$ & $\mathrm{S}\left(W / m^{2}\right)$ & $\mathrm{E}(V / m)$ & $\mathrm{H}(A / m)$ \\
\hline 850 & 33,06 & 87 & 0,38 \\
1900 & 23,09 & 63 & 0,38 \\
2400 & 10 & 61 & 0,16 \\
\hline
\end{tabular}

\section{RESULTS AND DISCUSSION}

From the developed system of measurement of electromagnetic pollution on a GIS, it has been possible to zone the places of the city that present the highest levels of pollution. This information is obtained in real time by means of the sensors strategically located according to the plans of territorial ordering. The information obtained can be correlated with localized health problems determined by local and territorial health entities and can be used for prevention projects by municipal authorities.

From the GIS system it is possible to obtain other electromagnetic pollution map models in threedimensional format that can serve as a location system in geographically rugged areas such as the area of development of this study as shown in Figure 5. The methodology developed in this research can be applied to other types of pollution correlation studies, such as atmospheric pollution, with health problems that are monitored by means of IoT technologies. This type of development allows the approach of populations to smart city processes and the development of public policies focused on the solution and management of problems that affect public health. 


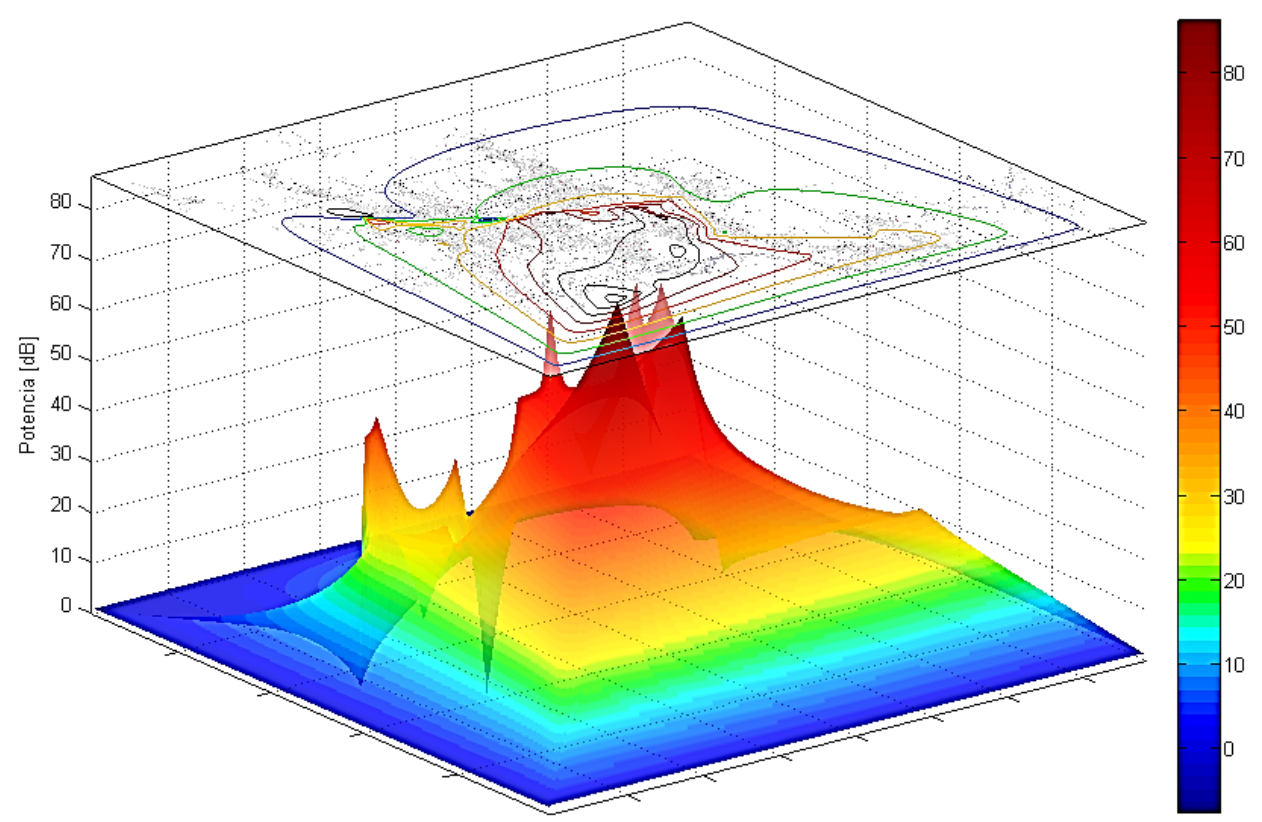

Figure 5. Layer of EM pollution levels in the city of manizales

\section{CONCLUSION}

This article presented the development of a GIS that will allow correlating the levels of electromagnetic pollution with information on clusters of diseases, so that it is possible to monitor the behavior of these two variables and contribute to the scientific world in their interest to know the possible risks that electromagnetic pollution generates on public health. For the development of the GIS it was required the incorporation of a methodology for the calculation of the electromagnetic pollution emitted by the BTS, in such a way that it was possible to generate the layer of pollution. By carrying out a visual inspection of this layer, it was possible to observe that the levels of pollution are heterogeneous in the city, in sites such as the city centre the highest values are presented, and in sites located on the outskirts of the city the levels are lower. It is expected that when a significant volume of data is available, it will be possible to corroborate the dynamics of the pathologies in relation to the levels of contamination reflected in the respective layer.

\section{ACKNOWLEDGEMENTS}

This work was supported by the Universidad Católica de Manizales with the research groups on Technological and Environmental Development GIDTA, and Education and Educators Traning EFE.

\section{REFERENCES}

[1] M. Suryanegara, "5G as disruptive innovation: Standard and regulatory challenges at a country level," Int. J. Technol., vol. 7, no. 4, pp. 635-642, 2016, doi: 10.14716/ijtech.v7i4.3232.

[2] G. Redlarski et al., "The influence of electromagnetic pollution on living organisms: Historical trends and forecasting changes," Biomed Res. Int., vol. 2015, 2015, doi: 10.1155/2015/234098.

[3] International Agency for Research on Cancer, "International Agency for Research on Cancer Iarc Monographs on the evaluation of carcinogenic risks to humans," IARCPRess, Lyon, France, 2002, doi: 10.1002/food.19940380335.

[4] I. B. Oluwafemi, A. M. Faluru, and T. D. Obasanyo, "Radio frequency peak and average power density from mobile base stations in Ekiti State, Nigeria," Bulletin of Electrical Engineering and Informatics (BEEI), vol. 10, no. 1, pp. 224-231, 2020, doi: 10.11591/eei.v10i1.1879.

[5] Cisco, "Cisco Annual Internet Report (2018-2023)," 2020.

[6] Ericsson Inc, "More than 50 Billion connected devices-taking connected devices to mass market and profitability," 2011. [Online]. Available: https://vdna.be/publications/Wp-50-Billions.Pdf.

[7] V. Reddy and Gayatri P., "Integration of internet of things with wireless sensor network," International Journal of Electrical and Computer Engineering (IJECE), vol. 9, no. 1, pp. 439-444, 2019, doi: 10.11591/ijece.v9i1.pp439444. 
[8] F. Arena and G. Pau, "An overview of big data analysis," Bulletin of Electrical Engineering and Informatics (BEEI), vol. 9, no. 4, pp. 1646-1653, 2020, doi: 10.11591/eei.v9i4.2359.

[9] R. Woodhead, "Building a smarter city," Int. J. Technol., vol. 9, no. 7, pp. 1509-1517, 2018, doi: 10.14716/ijtech.v9i7.2734.

[10] K. H. Kim, E. Kabir, and S. A. Jahan, "The use of cell phone and insight into its potential human health impacts," Environ. Monit. Assess., vol. 188, no. 4, p. 221, 2016, doi: 10.1007/s10661-016-5227-1.

[11] A. Kuzniar et al, "Semi-quantitative proteomics of mammalian cells upon short-term exposure to nonionizing electromagnetic fields," PLoS One, vol. 12, no. 2, pp. 1-25, 2017, doi: 10.1371/journal.pone.0170762.

[12] D. F. da Silva, W. R. Barros, M. da C. C. de Almeida, and M. A. V. Rêgo, "Exposure to non-ionizing electromagnetic radiation from mobile telephony and the association with psychiatric symptoms," Cad. Saude Publica., vol. 31, no. 10, pp. 2110-2126, 2015, doi: 10.1590/0102-311X00104114.

[13] A. C. Dode et al., "Mortality by neoplasia and cellular telephone base stations in the Belo Horizonte municipality, Minas Gerais state, Brazil," Sci. Total Environ., vol. 409, no. 19, pp. 3649-3665, 2011, doi: 10.1016/j.scitotenv.2011.05.051.

[14] M. Havas, "When theory and observation collide: Can non-ionizing radiation cause cancer?" Environ. Pollut., vol. 221, pp. 501-505, 2017, doi: 10.1016/j.envpol.2016.10.018.

[15] B. B. Levitt and H. Lai, "Biological effects from exposure to electromagnetic radiation emitted by cell tower base stations and other antenna arrays," Environ. Rev., vol. 18, pp. 369-395, 2010, doi: 10.1139/A10-018.

[16] L. L. Morgan, A. B. Miller, A. Sasco, and D. L. Davis, "Mobile phone radiation causes brain tumors and should be classified as a probable human carcinogen (2A) (Review)," Int. J. Oncol., vol. 46, no. 5, pp. 1865-1871, 2015, doi: 10.3892/ijo.2015.2908.

[17] D. Shahbazi-Gahrouei, M. Karbalae, H. A. Moradi, and M. Baradaran-Ghahfarokhi, "Health effects of living near mobile phone base transceiver station (BTS) antennae: A report from Isfahan, Iran," Electromagn. Biol. Med., vol. 33, no. 3, pp. 206-210, 2014, doi: 10.3109/15368378.2013.801352.

[18] L. Yang, D. Hao, M. Wang, Y. Zeng, S. Wu, and Y. Zeng, "Cellular neoplastic transformation induced by 916 MHz microwave radiation," Cell. Mol. Neurobiol., vol. 32, no. 6, pp. 1039-1046, 2012, doi: 10.1007/s10571-0129821-7.

[19] J. M. Pearce, "Limiting liability with positioning to minimize negative health effects of cellular phone towers," Environ. Res., vol. 181, p. 108845, 2020, doi: 10.1016/j.envres.2019.108845.

[20] N. J. van Eck and L. Waltman, "Software survey: VOSviewer, a computer program for bibliometric mapping," Scientometrics, vol. 84, pp. 523-538, 2010, doi: 10.1007/s11192-009-0146-3.

[21] World Health Organization, "Campos electromagnéticos y salud pública," 2007. [Online]. Available: https://www.who.int/peh-emf/publications/facts/fs322/es/.

[22] S. Puttinaovarat et al., "Facility maintenance management system based on GIS and indoor map," International Journal of Electrical and Computer Engineering (IJECE), vol. 9, no. 4, pp. 3323-3332, 2019, doi: 10.11591/ijece.v9i4.pp3323-3332.

[23] J. M. Paniagua, M. Rufo, A. Jimenez, and A. Antolin, "The spatial statistics formalism applied to mapping electromagnetic radiation in urban areas," Environ. Monit. And Assess., vol. 185, pp. 311-322, 2013, doi: 10.1007/s10661-012-2555-7.

[24] M. Rufo, A. Antolín, J. M. Paniagua, and A. Jiménez, "Optimization and comparison of three spatial interpolation methods for electromagnetic levels in the AM band within an urban area," Environ. Res., vol. 162, pp. 219-225, 2018, doi: 10.1016/j.envres.2018.01.014.

[25] I. Calvente et al., "Outdoor characterization of radio frequency electromagnetic fields in a Spanish birth cohort," Environ. Res., vol. 138, pp. 136-143, 2015, doi: 10.1016/j.envres.2014.12.013.

[26] A. M. Rinaldi, "A GIS-based system for electromagnetic risk management in urban areas," J. Locat. Based Serv., vol. 3, no. 1, pp. 3-23, 2009, doi: 10.1080/17489720902776720.

[27] D. Briggs, L. Beale, J. Bennett, M. B. Toledano, and K. de Hoogh, "A geographical model of radio-frequency power density around mobile phone masts," Sci. Total Environ., vol. 426, pp. 233-243, 2012, doi: 10.1016/j.scitotenv.2012.03.066.

[28] J. L. Soto-Sumuano, F. J. Olivera-Guerrero, J. A. Tlacuilo-Parra, R. G. Covarrubias, H. Romo-Rubio, and E. Abundis-Gutierrez, "Geographical Information System for patients, neoplasms and associated environmental contamination," in Comput. Sci. Its Appl. - ICCSA 2017, 2017, pp. 284-298, doi: 10.1007/978-3-319-62407-5.

[29] V. H. Céspedes, L. F. D. Cadavid, and Y. A. G. Gómez, "Electromagnetic pollution maps as a resource for assessing the risk of emissions from mobile communications antennas," International Journal of Electrical and Computer Engineering (IJECE), vol. 10, no. 4, pp. 4244-4251, 2020, doi: 10.11591/ijece.v10i4.pp4244-4251.

[30] QGIS, "A Gentle Introduction to GIS," 2020. [Online]. Available: https://docs.qgis.org/testing/en/docs/gentle gis introduction/spatial analysis interpolation.html.

[31] P. G. Nejad, A. Ahmad, and I. S. Zen, "Assessment of the interpolation techniques on traffic noise pollution mapping for the campus environment sustainability," Int. J. Built Environ. Sustain., vol. 6, no. 1-2, pp. 147-159, 2019, doi: 10.11113/ ijbes.v6.n1-2.393.

[32] "Decreto 1370 de 02 de Agosto del 2018," Ministerio de tecnologías de la información y las comunicaciones, Mininformación, Colombia, 2018.

[33] "Guidelines for limiting exposure to time - varying electric, magnetic and electromagnetic fields (up to $300 \mathrm{GHz}$ ), Health Phys.," International Commission on Non - Ionizing Radiation Protection (ICNIRP), 1999. 


\section{BIOGRAPHIES OF AUTHORS}
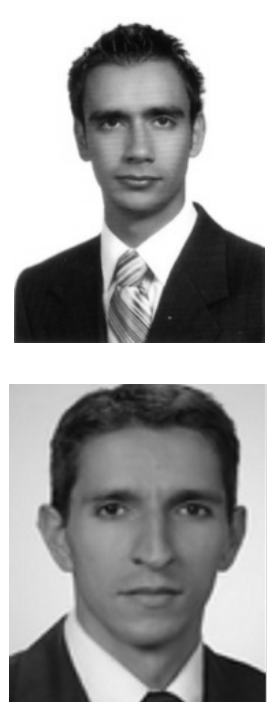

Vladimir Henao Céspedes received the B.S degree in electronic engineering, the M.Sc. degree and the PhD. On engineering from Universidad Nacional de Colombia, Manizales. He currently an Associate Professor in the Faculty of Engineering and Architecture, telecommunications engineering, at the Universidad Católica de Manizales, Manizales. E-mail: vhenao@ucm.edu.co. His research interests include electromagnetic compatibility, electromagnetic pollution, and lightning discharges. He is member of the Research Group on Tecnhonological and Environmental Development GIDTA. http://orcid.org/0000-0002-1938-3203

Yeison Alberto Garces-Gómez Electrical Engineer, M.Sc (Eng) Industrial Automation, Ph.D. on Engineering. Titular Professor, UAFCNM, Universidad Católica de Manizales, Manizales, Colombia. E-mail: ygarces@ucm.edu.co. His research interests include power definitions under no sinusoidal conditions, power quality analysis, power electronic applications and technologies applied to health and education. He is member of the Research Group on Tecnhonological and Environmental Development GIDTA and Education and Educators Traning EFE. http://orcid.org/0000-0002-9409-3652 